\title{
Chromatographic fingerprint of the volatile fraction of rare Hedera helix honey and biomarkers identification
}

\author{
Ewa Makowicz ${ }^{1} \cdot$ Paweł Kafarski $^{2} \cdot$ Izabela Jasicka-Misiak $^{1}$
}

Received: 12 March 2018 / Revised: 10 July 2018 / Accepted: 14 July 2018 / Published online: 30 July 2018

(c) The Author(s) 2018

\begin{abstract}
Hedera helix (Irish ivy) honey is a very rare food product used in Ireland. The composition of the volatile fraction of this unique honey was studied for the first time using three different extraction procedures (SPE, USE and HS-SPME) and analyzed with gas chromatography and mass spectrometry. As expected, the use of combined techniques resulted in the identification of the detailed composition of honey volatiles. Identified constitutes belongs to the different chemical classes. The presence of $4(1 H)$-quinolinone, myrtenal and phenylacetonitrile was proposed as biomarkers of the botanical origin of ivy honey. Moreover, they are not widely widespread among honeys of different botanical origins. Additional usefulness of the HPTLC studies was documented by showing that this method allows obtaining characteristic patterns of honey fractions enabling a simple visual determination of honey authenticity.
\end{abstract}

Keywords Ivy honey $\cdot$ Honey volatiles $\cdot$ HPTLC $\cdot$ HS-SPME $\cdot$ Honey authentication

\section{Introduction}

Honey, which is a complex natural food product with various physicochemical properties, is one of the most consumerpreferred, bee products in the world. The composition and properties of this cocktail largely depends on the melliferous plant species, but also on other agents such geographic area, season, mode of storage, and harvest technology and conditions $[1,2]$.

The honey made by bees from different botanical sources may have distinctly different organoleptic properties (color, aroma and taste). Particular differences are observed in its aroma, due to differences in volatile composition. Moreover, composition of volatile compounds strongly depends on varied factors, such as from botanical and geographical origin, climate, soil, age of honey, mode of storage, honey processing and bee species. Furthermore in case of isolation of volatiles from honey samples, the extraction procedure

Izabela Jasicka-Misiak

izajm@uni.opole.pl

1 Faculty of Chemistry, Opole University, Oleska 48, 45-052 Opole, Poland

2 Faculty of Chemistry, Wroclaw University of Science and Technology, ul. Wybrzeże Wyspiańskiego 27, 50-370 Wrocław, Poland is crucial and significant differences are observed among the same honeys based on used method of extraction [3-5]. Monofloral honeys, with a defined botanical origin are considered as the highest quality product and are sold all over the world at higher prices than multifloral honey. However, all types of honey, like other food products, shall meet the requirements for organoleptic as well as physical and chemical properties.

Results of quality control and nutritional value of food products around the world clearly indicates that monofloral honey fall within the category of most frequently adulterated food products [6,7]. Determination of these adulterations is not an easy task because commonly used, classical procedures of honey analysis and classification (pollen analysis) possess some limitations as a result of which they frequently fail. The identification of natural products, which are present in honey at low concentrations, offers a possibility to solve this problem. These small-molecular compounds are deciding about taste, dietary and therapeutic value of honeys. The knowledge of the structure and content of volatile compounds in various types of honey might result in a better understanding of honey's flavor and nutrient, as well as-even more important-their therapeutic value [8-13]. Investigation of volatile compounds of honey seem to be the right solution, which might help to standardize the quality and authenticity of the product [14]. English Ivy honey is a 
monofloral variety made from the flower nectar and pollen of the common ivy (Hedera helix). Ivy is an evergreen vine which we can observe on fences, houses, trees and even in such unexpected places as cliffs. Although it is known as an invasive species, the plant is widely used as an ornamental green facade for various buildings. In first months after harvesting the honey produced from its flowers has a strong and unpleasant taste. Commonly, ivy produces nectar-rich, small, yellow-green, and umbrella-like flowers. The nectar is particularly appealing to honey bees because it is sweet and found in generous amounts. Moreover it is available from the end of summer until the end of autumn, and this is the time when other food sources for honey bees are limited. It is difficult to remove $H$. helix honey from bee combs even if, it is harvested in time since it crystallizes in a short period of time (around 2 weeks). It is occurring mainly because of the high content of glucose. The ivy honey contain usually up to $80 \%$ of it [15].

This is an extremely rare brand of honey, and thus according to the best of our knowledge, the chemical composition of ivy honey so for was characterized based on one sample collected in Corsican Arbutus unedo habitat [16]. Therefore, the main objective of this study was to use different extraction procedures (ultrasound solvent extraction, solidphase extraction and headspace solid-phase microextraction) combined with chromatographic analysis to create a unique chemical fingerprint of the volatile fraction of $H$. helix honey which could be useful for future evaluate of its authenticity.

\section{Materials and methods}

\section{Reagents and materials}

All used chemicals were of analytical grade. Dichloromethane, toluene, ethanol, methanol, ethyl acetate, glacial acetic acid, 95\% sulfuric acid and anhydrous magnesium sulfate were purchased from POCH S.A. (Gliwice, Poland). Anisaldehyde, the homologous series of $n$-alkanes $\mathrm{C}_{9}-\mathrm{C}_{25}$, and all compounds used as references substances were purchased from Sigma-Aldrich (Poznań, Poland). Strata SDB-L SPE cartridges were purchased from Phenomenex and silica gel 60 HPTLC aluminum plates $(20 \mathrm{~cm} \times 10 \mathrm{~cm})$ were purchased from Merck.

\section{Honey samples and melissopalynological analysis}

It this study, we used a very rare Irish ivy honey (H. helix) collected from small domestic apiaries in the Republic of Ireland in 2016 and 2017 (for each year three honey samples were collected and analyzed). Honey samples were hermetically closed and kept at $4{ }^{\circ} \mathrm{C}$ in the dark before analysis. All honey samples were subjected to pollen analysis, which was performed on an Olympus BX41 microscope under $400 \times$ magnification. It was performed according to the recommendation of the International Commission of Bee Botany and by the International Honey Commission [17].

\section{Extraction and determination of volatile compounds}

\section{Ultrasound solvent extraction (USE)}

Ultrasound solvent extraction was performed as described previously with some modification $[18,19]$. Twenty grams of ivy honey was placed in a $100 \mathrm{ml}$ flask and dissolved in $12 \mathrm{ml}$ of distilled water followed by the addition of $0.80 \mathrm{~g}$ of anhydrous magnesium sulfate. The aqueous solutions were then extracted with $10 \mathrm{ml}$ of dichloromethane using an ultrasonic cleaning bath (Cole-Parmer 8891) at $25^{\circ} \mathrm{C}$ for $30 \mathrm{~min}$. After sonication, the whole extract was centrifuged at $3000 \mathrm{rpm}$, and the organic layer was collected. Each sample was extracted three times with a new portion of the solvent. The organic layers were combined, dried over anhydrous magnesium sulfate and concentrated under a nitrogen gas stream. The procedure was performed in triplicate with the same amount of honey. The resulting oily residues were dissolved in $350 \mu \mathrm{l}$ of dichloromethane and stored at $4{ }^{\circ} \mathrm{C}$ until HPTLC and GC-MS analysis.

\section{Solid-phase extraction (SPE)}

SPE was performed as described previously with some modification $[18,19]$. The entire procedure was carried out in a Baker SPE-12G vacuum manifold (J. T. Baker ${ }^{\circledR}$, Phillipsburg, NJ, USA) at a flow rate of $1.5 \mathrm{ml} / \mathrm{min}$ using $3 \mathrm{ml}$ Strata SDB-L cartridges with $200 \mathrm{mg}$ of styrene-divinylbenzene resin (Phenomenex). Prior to use, the cartridges were conditioned by rinsing with $6 \mathrm{ml}$ of dichloromethane, $6 \mathrm{ml}$ of water, and $6 \mathrm{ml}$ of an ethanol-water mixture $(12 \%, \mathrm{v} / \mathrm{v})$. $10 \mathrm{~g}$ of ivy honey was dissolved in $25 \mathrm{ml}$ of distilled water, filtered through a filter paper and passed through the cartridges. Then, the remaining sugars and other hydrophilic components were flushed out with $15 \mathrm{ml}$ of water. Finally, elution of the desired components was performed with $10 \mathrm{ml}$ of dichloromethane. The obtained organic extracts were dried over anhydrous magnesium sulfate and concentrated under a stream of nitrogen gas. The procedure was performed in triplicate with the same amount of honey. The resulting oily residues were dissolved in $350 \mu \mathrm{l}$ of dichloromethane and stored at $4{ }^{\circ} \mathrm{C}$ until HPTLC and GC-MS analysis. 


\section{Headspace solid-phase microextraction (HS-SPME)}

In this study, two types of SPME fibers purchased from Supelco (Bellefonte, PA, USA) were used: $65 \mu \mathrm{m}$ PDMS/ DVB (polydimethylsiloxane/divinylbenzene) and 50/30 $\mu \mathrm{m}$ PDMS/CAR/DVB (divinylbenzene/carboxen/polydimethylsiloxane) with the needle size $24 \mathrm{ga}$ in both cases. The HS-SPME experiments were performed using a manual holder. Before analysis, the fibers were conditioned according to the attached instruction. The optimal extraction parameters of H. helix honey volatiles were chosen as follows: $5 \mathrm{~g}$ of honey was dissolved with $5 \mathrm{ml}$ of distilled water and $0.75 \mathrm{~g}$ of $\mathrm{NaCl}$ was added to the vial. Initially, the samples were conditioned in a thermostatic bath at $70 \pm 1.0^{\circ} \mathrm{C}$ for $15 \mathrm{~min}$ under constant agitation. After this period, the septum was pierced with a needle and the fiber was exposed to the headspace for $30 \mathrm{~min}$ at $70 \pm 1.0^{\circ} \mathrm{C}$. The extracted analytes were thermally desorbed in the injection port of GC-MS at $250{ }^{\circ} \mathrm{C}$ for $5 \mathrm{~min}$. All analyses were performed in triplicate for each honey sample and fiber.

\section{GC-MS analysis}

GC-MS analyses were carried out on an HP 6890 GC system (Hewlett Packard, Böblingen, Germany) equipped with a $30 \mathrm{~m} \times 0.25 \mathrm{~mm}$ i.d. capillary column with an HP-5 MS [(5\%-phenyl)-methylpolysiloxane, Agilent J and WGC column] with a coating thickness of $0.25 \mu \mathrm{m}$ coupled to a 5973 Mass Selective Detector (Hewlett Packard, Böblingen, Germany). For the analysis of extracts obtained by USE, SPE and by HS-SPME, the mass detector was used in the electron impact ion-ionization mode at $70 \mathrm{eV}$, and the mass range was 35-500 Daltons. The ion source temperature was $230^{\circ} \mathrm{C}$, and the transfer line and injector temperature were kept at $250{ }^{\circ} \mathrm{C}$. For USE and SPE extracts, the GC was fitted with a split injection liner and the operated split was 1:10. Moreover, 2 min solvent delay time was set. For HS-SPME, a splitless injection liner suitable for SPME was used. Helium, at a constant flow rate of $2 \mathrm{ml} / \mathrm{min}$, was used as the carrier gas. The oven temperature was programed as follows: the initial oven temperature was held at $45^{\circ} \mathrm{C}$ for $3 \mathrm{~min}$, increased to $180{ }^{\circ} \mathrm{C}$ at a rate of $5{ }^{\circ} \mathrm{C} / \mathrm{min}$, and finally increased to $250{ }^{\circ} \mathrm{C}$ at a rate of $10{ }^{\circ} \mathrm{C} / \mathrm{min}$ and held isothermally for $10 \mathrm{~min}$ for the extracts after USE and SPE, and for HS-SPME extract: $3 \mathrm{~min}$ at $40{ }^{\circ} \mathrm{C}$, increased to $150{ }^{\circ} \mathrm{C}$ at a rate of $3{ }^{\circ} \mathrm{C} / \mathrm{min}$, and finally increased to $200{ }^{\circ} \mathrm{C}$ at a rate of $10^{\circ} \mathrm{C} / \mathrm{min}$ and held isothermally for $10 \mathrm{~min}$. For all methods benzophenone as an internal standard was used (for USE and SPE extracts was added just before injection and for HS-SPME to the honey before extraction). Identification of the compounds was performed based on the comparison of their mass spectra with those present in the NIST 11 Library (National Institute of Standards and Technology,
Gaithersburg, MD, USA) and with the retention indices calculated for each peak relative to $\mathrm{C}_{9}-\mathrm{C}_{25} n$-alkanes for the HP-5 MS column. The obtained values were compared with those present in the literature (NIST Chemistry WebBook, NIST Standard Reference Database Number 69, http:// webbook.nist.gov/chemistry/) or with standard substances available from our laboratory. Each sample was analyzed three times, and average peak areas were calculated from the GC using the normalization method without a correction factor.

\section{High performance thin layer (HPTLC) separation}

High performance thin layer analyses of the obtained $H$. helix extracts after USE and SPE were performed as described previously, with some modification [19], on precoated silica gel 60 HPTLC aluminum plates $(20 \mathrm{~cm} \times 10 \mathrm{~cm})$. Ten microliters of each extract was applied to the plate in $13 \mathrm{~mm}$ bands $15 \mathrm{~mm}$ from the lower edge of the plate at a rate of $250 \mathrm{nl} \cdot \mathrm{s}-1$ using a semi-automated HPTLC application device (Linomat 5, CAMAG, Muttenz, Switzerland) under the flow of nitrogen gas. The chromatographic separation was performed in a chromatographic tank, which was saturated for $20 \mathrm{~min}$ with the mobile phase toluene-ethyl acetate $[80: 20(\mathrm{v} / \mathrm{v})]$ and developed to a distance of $95 \mathrm{~mm}$. Then, the plates were derivatized with anisaldehyde reagent (prepared as follows: $10 \mathrm{ml}$ of glacial acetic acid was added to $0.5 \mathrm{ml}$ of anisaldehyde and diluted by $85 \mathrm{ml}$ of methanol, followed by dropwise addition of $10 \mathrm{ml}$ of concentrated sulfuric acid). After derivatization, the HPTLC plates were dried at $105{ }^{\circ} \mathrm{C}$ for $5 \mathrm{~min}$. The results were documented both after and before derivatization using a HPTLC imaging device (TLC Visualizer, CAMAG) under white light, and by irradiation at $254 \mathrm{~nm}$ and at $366 \mathrm{~nm}$ using a software (visionCATS, CAMAG).

\section{NMR measurements}

${ }^{1} \mathrm{H}$ NMR experiments were performed on a $400 \mathrm{MHz}$ Bruker Ultrashield (Bruker, Rheinstetten, Germany). Measurements were done in $\mathrm{CDCl}_{3}(99.8$ atom \% D) solution at $297 \mathrm{~K}$. All chemical shifts presented in the text are reported in parts per million relative to $\mathrm{CDCl}_{3}$, which was used as an external standard.

\section{Results and discussion}

In this paper, samples of Irish honey collected in 2016 and 2017 were studied. The botanical origin of honey was confirmed by melissopalynological analysis. In the case of the samples from 2016, the lowest percentage of $H$. helix pollen was 87 with $13 \%$ of other undefined pollen grains, whereas 
for honey collected in 2017 the lowest percentage of $\mathrm{H}$. helix pollen was also dominating (92\%) over other undefined pollen grains. Ivy honey is characterized by a specific taste and unusual, strong $H$. helix aroma, which could be unpleasant in the first few months after harvesting [15].

To obtain more complete results and to isolate the volatiles, three different methods of extraction were applied: ultrasonic solvent extraction (USE), solid-phase extraction (SPE) and headspace solid-phase microextraction (HS-SPME) with two types of fibers (PDMS/DVB (polydimethylsiloxane/divinylbenzene) and PDMS/CAR/DVB [divinylbenzene/carboxen/polydimethylsiloxane)]. GC-MS analysis of the obtained extracts allowed the identification of 84 volatile compounds, which represent various chemical entities, such as terpenes, benzene derivatives, esters, aldehydes, ketones, saturated and unsaturated hydrocarbons and others. The detailed results of these analyses are presented in Table 1. It is not surprising that the obtained results indicated the influence of the isolation method on volatile fraction composition. Significant qualitative differences between the chemical profiles obtained by USE and SPE methods in comparison with HS-SPME were observed.

The headspace profile of Ivy honey obtained by HS-SPME revealed the presence of 62 compounds when using both fibers and only small differences in their composition were observed. The most abundant chemical constitutes are phenylacetonitrile $(4.36 \% / 15.25 \%)$, myrtenal $(1.28 \% / 1.47 \%), \beta$-damascenone $(2.55 \% / 2.32 \%)$, phenylacetaldehyde (2.15\%/4.71\%), 2-methyl-5-(1,1,5-trimethyl-5-hexenyl)furan $(9.49 \% / 8.59 \%), \alpha$-isophorone $(1.32 \% / 1.79 \%)$ and 3,4,5-trimethylphenol (2.03\%/3.23\%). Additionally, higher aliphatic compounds, albeit in lower concentrations, were determined in the obtained extracts, such as $n$-hexadecanoic acid, pentadecane, nonadecane, ethyl heptanoate, ethyl heptanoate and (Z,Z)-9,12-octadecadienoic acid.

In contrast, only 33 of the compounds were identified using both USE and 34 using SPE. Among them, the most abundant are: $4(1 H)$-quinolinone/5(1H)-quinolinone/2(1H)quinolinone (15.52\% for USE and $31.68 \%$ for SPE), isoquinoline (2.27\% for USE and $1.15 \%$ for SPE), phenylacetonitrile (6.21\% for USE and 5.97\% for SPE), phenylacetic acid (1.47\% for USE and $2.06 \%$ for SPE) and cis/trans-linalool oxide (furan type) $(1.19 \% / 1.97 \%$ for USE and $0.83 \% / 1.62 \%$ for SPE). Moreover, as in the case of HS-SPME extracts, several higher nonpolar hydrocarbons, fatty acids and their esters were also identified in small concentrations. The most abundant are: 1-docosene, $(Z)$-octadec-9-enal, $(Z, Z)$ 9,12-octadecadienoic acid, ethyl decanoate, $n$-hexadecanoic acid, nonadecane and tricosane. These compounds are, however, characteristic for various monofloral and polyfloral honey.

Among the obtained fraction, few compounds belonging to the terpenes were identified with cis/trans linalool oxide (furan type), p-cymene, eugenol, myrtenal and $p$-cymenene being the most abundant. Additionally, some examples of compounds, which represent a class of degraded carotenoids $\mathrm{C}_{9}$-norisoprenoids, namely, 4-oxoisophorone, 4-hydroxyisophorone, $\beta$-isophorone, $\alpha$-isophorone as well as $\beta$-damascene, a $\mathrm{C}_{15}$-norisoprenoid, were identified. It is worth mentioning that in contrast to the HS-SPME method, only 4-ketoisophorone and $\beta$-damascene were identified when using USE and SPE. In all of the extracts' compounds, 3,4,5-trimethylphenol, benzoic acid, phenylacetaldehyde, 3-hydroxy-4-methoxybenzaldehyde, benzaldehyde, acetophenone, 4-hydroxyacetophenone, $o$-methoxyacetophenon and the most abundant phenylacetonitrile were identified belonging to benzene derivatives. Even though they individually are present in rather minor concentrations, taking all together they are important contributors to the $H$. helix honey aroma creation. Moreover, they are widespread among different honey varieties [20]. As seen from Table 1, all of these compounds are present as minor constituents of the obtained fractions. Furthermore, some of these compounds such as benzaldehyde, phenylacetaldehyde, nonanal, isophorone or benzyl nitrile were also previously identified in one H. helix honey from Corsica [16].

Additionally, compounds such as benzenacetic acid or cis/ trans-linalool oxide (furan type) benzenacetaldehye, compounds belong to $\mathrm{C}_{13^{-}}$and $\mathrm{C}_{9^{-}}$- norisoprenoids (products of carotenoids degradation), or benzene derivatives, which are native to honey are widespread in various brands of honey $[1,2,14,20-22]$ and cannot be considered as potential markers for the determination of honey's botanical origin.

The presence of quinoline derivatives together with quite high contents of phenylacetonitrile and myrtenal seems to be a characteristic combination, which could distinguish Ivy honey from other unifloral honey types, since there is limited information on the presence of these compounds in other monofloral honey.

Quinoline and isoquinoline alkaloids are derivatives of tryptophan and tyrosine, respectively, and they are widely distributed in nature. Initially, they were extracted from different natural resources, mostly from flowered plants. They exhibit variable biological functions such as antimalarial, anti-inflammatory, antimicrobial, or [23-25] analgesic functions. They are scarcely seen in the volatile fractions of honey. Previously, they were isolated and identified in chestnut honey in significant concentrations [26-28]. Isolated 2-quinolinol, 4-quinolinol and quinazolinone were proposed as its markers [26, 27]. In this study, only the presence of quinoline was undoubtedly confirmed based on the comparison of MS spectra obtained for this compound with the spectrum of the pure substance. The differentiation between 2(1H)-quinolinone, 4(1H)-quinolinone and 5(1H)quinolinone was impossible by this technique even using standards, because these compounds are structural isomers 


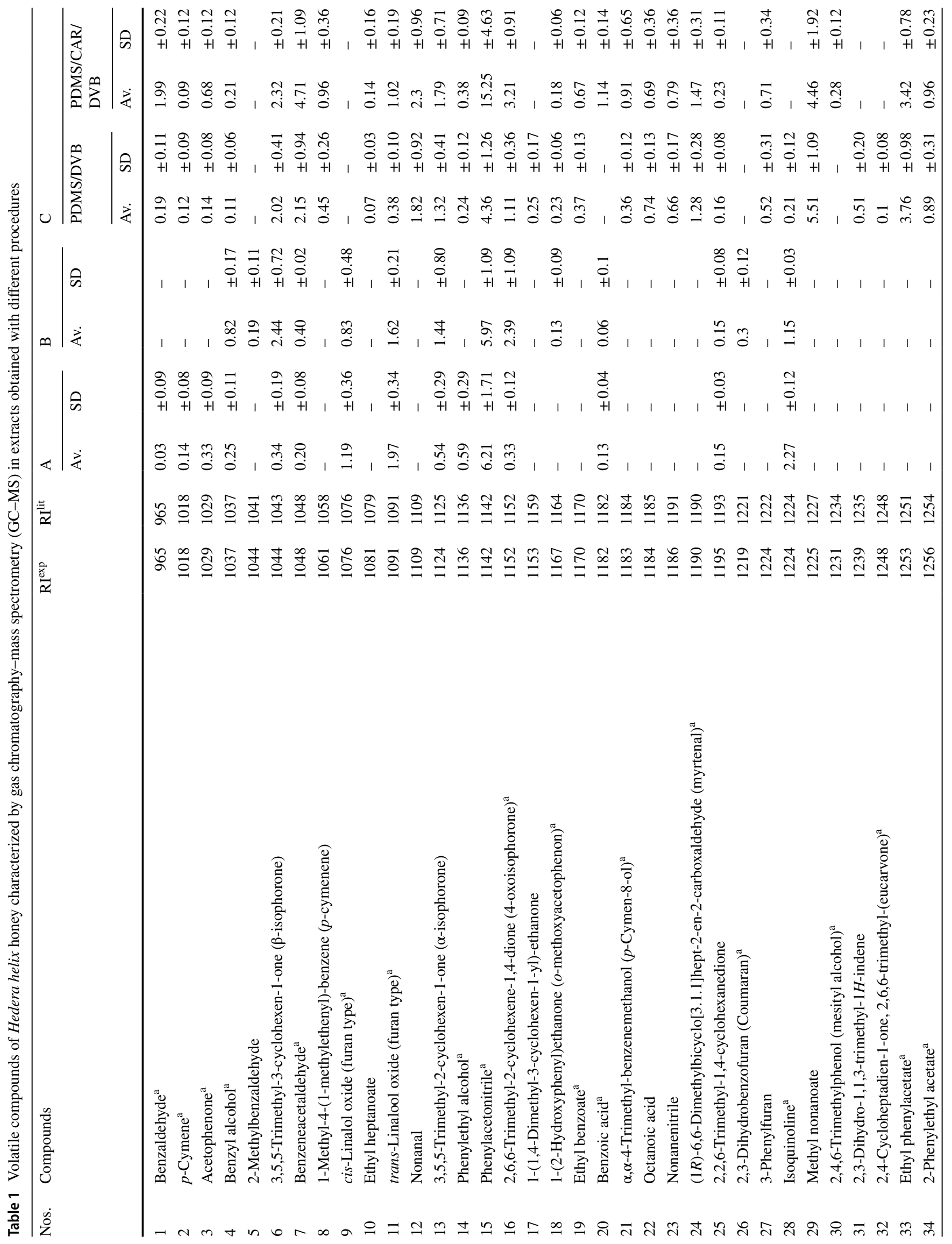




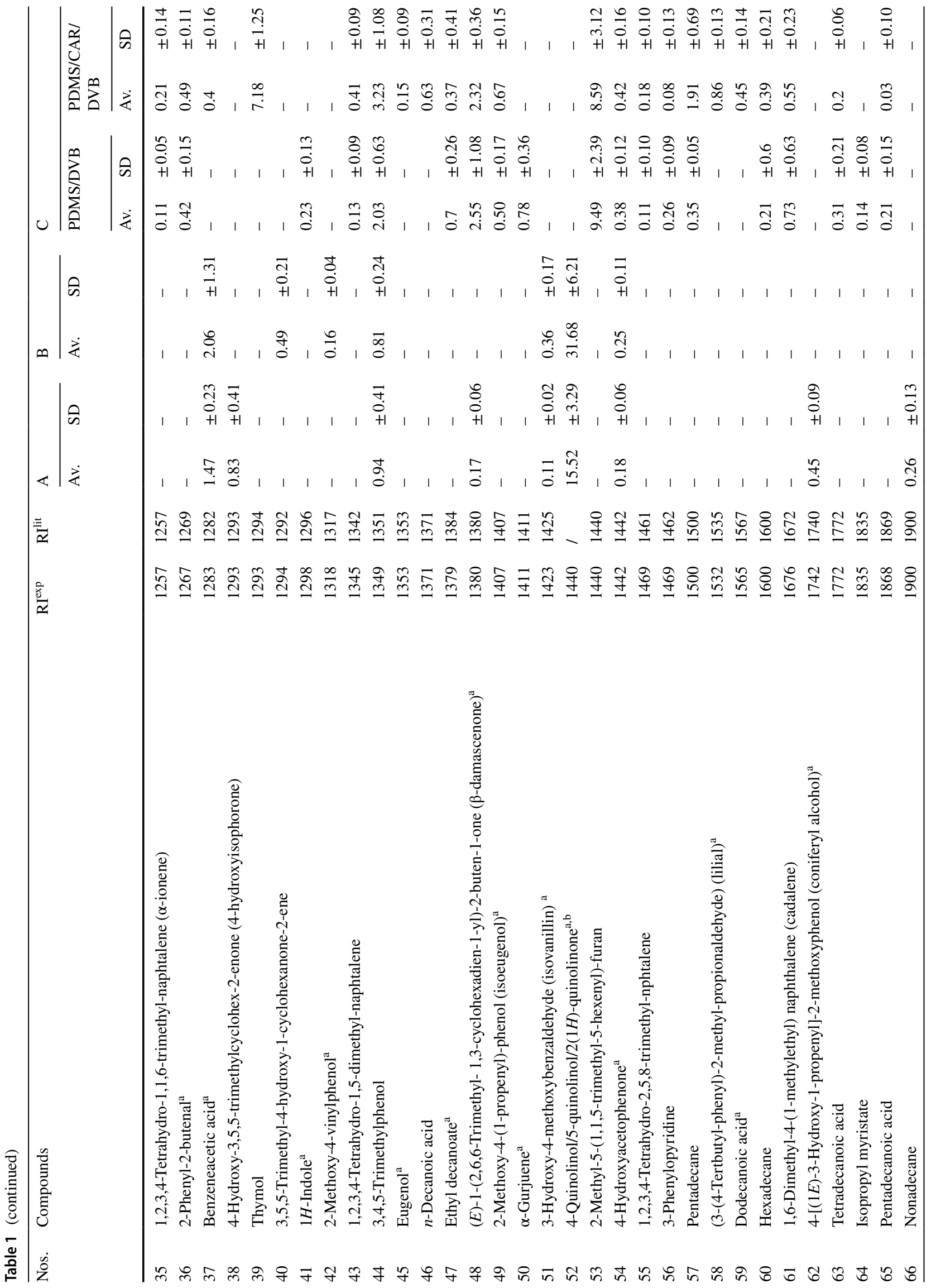




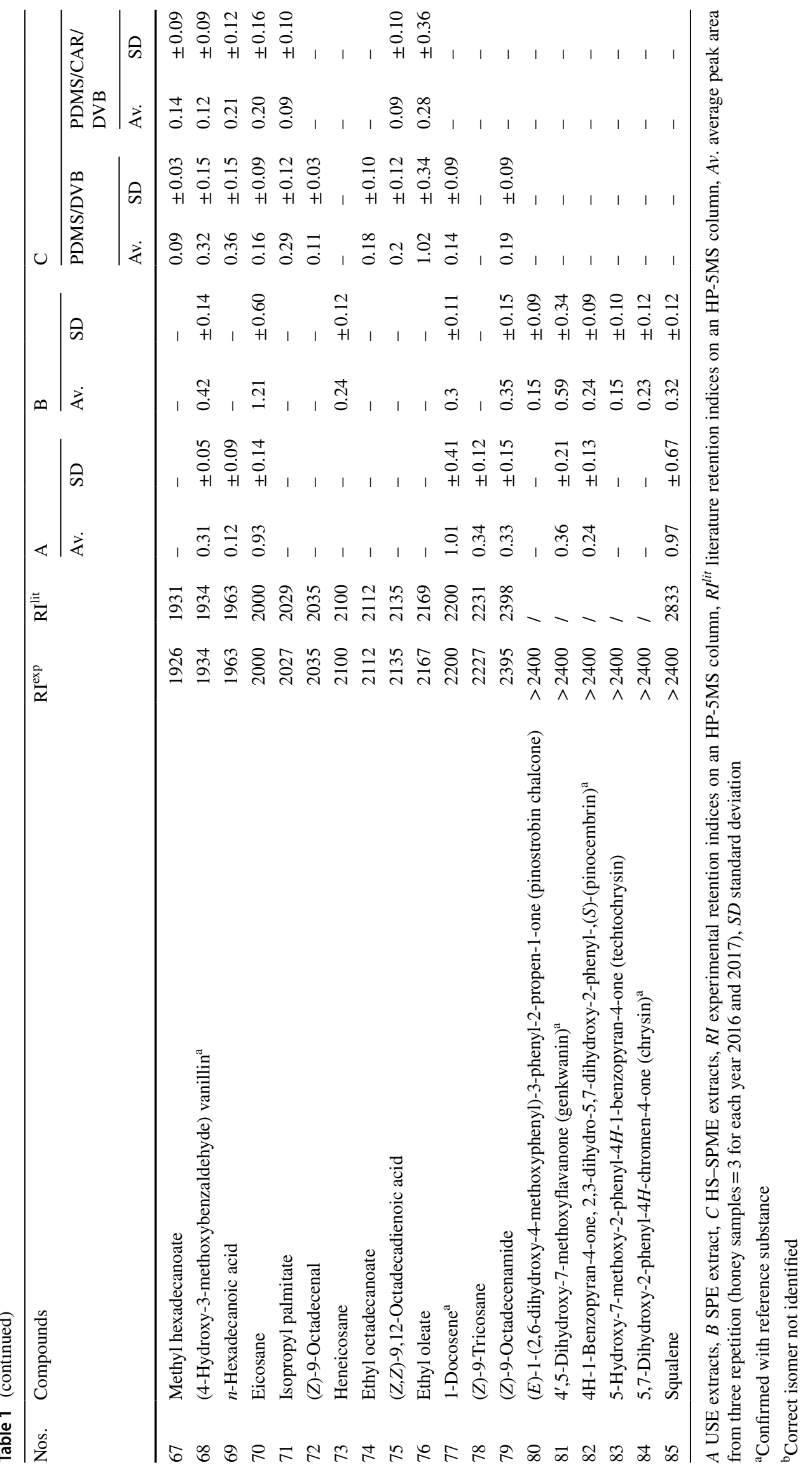




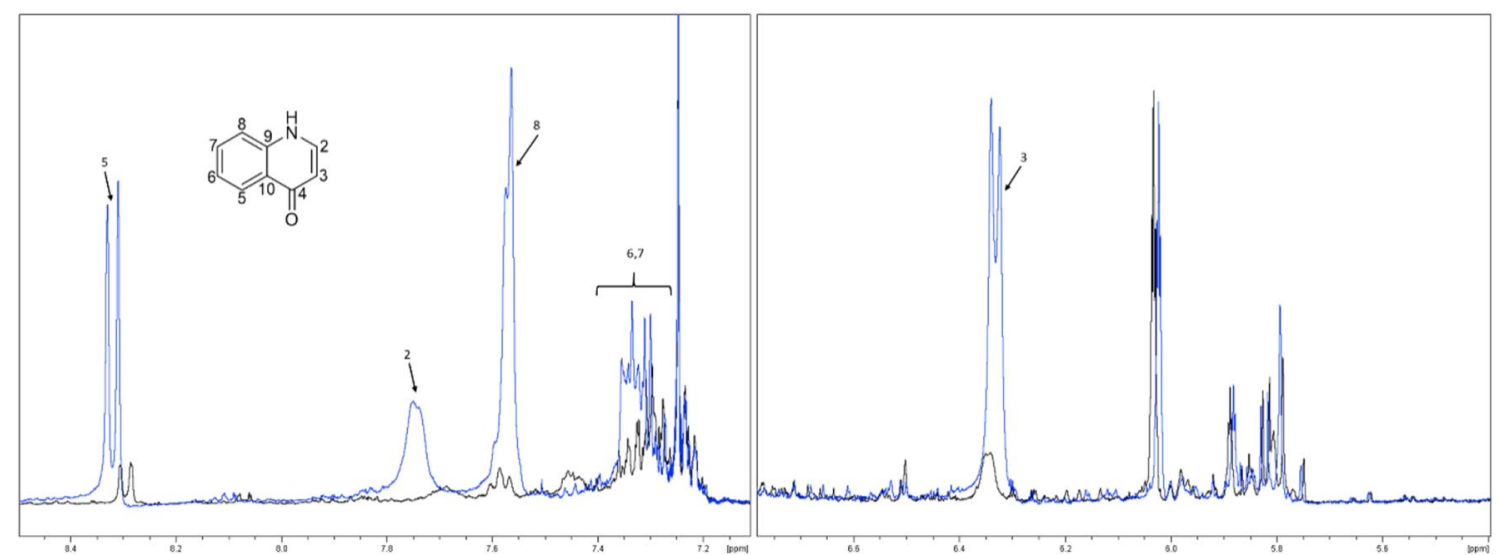

Fig. 1 Indicative fragments of ${ }^{1} \mathrm{H}$ NMR spectra of USE extract (black line) and the same extract enriched with 4(1H)-quinolinone (blue line)

Table $2{ }^{1} \mathrm{H}$ NMR data for pure $4(1 H)$-quinolinone and in enriched Hedera helix honey extracts

\begin{tabular}{lll}
\hline Position & $\begin{array}{l}\mathrm{A} \\
\delta_{\mathrm{H}}\end{array}$ & $\begin{array}{l}\mathrm{B} \\
\delta_{\mathrm{H}}\end{array}$ \\
\hline 1 & $10.15 \mathrm{~s}$ & $\mathrm{nd}$ \\
2 & $7.70 \mathrm{~d}$ & $7.70 \mathrm{~d}$ \\
3 & $6.3 \mathrm{~d}$ & $6.35 \mathrm{~d}$ \\
5 & $8.38 \mathrm{dd}$ & $8.33 \mathrm{dd}$ \\
6 & $7.38 \mathrm{t}$ & nd \\
7 & $7.49 \mathrm{~d}$ & nd \\
8 & $7.62 \mathrm{t}$ & $7.59 \mathrm{t}$ \\
\hline
\end{tabular}

Chemical shifts are given in parts per million

$A$ data for pure 4(1H)-quinolinone standard, $B$ data for $4(1 H)$-quinolinone enriched extract

with the molecular formula $\mathrm{C}_{9} \mathrm{H}_{7} \mathrm{NO}$ and thus have identical molecular mass. Thus, ${ }^{1} \mathrm{H}$ NMR experiments of SPE fractions spiked with appropriate standards were conducted. As seen from Fig. 1, the obtained results confirmed the presence of $4(1 H)$-quinolinone, while $2(1 H)$-quinolinone and $5(1 H)$-quinolinone were not detected in this manner. The comparisons of ${ }^{1} \mathrm{H}$ NMR chemical shifts recorded for pure $4(1 H)$-quinolinone and in extracts enriched with this compound are reported in Table 2.

Phenylacetonitrile belongs to the class of nitrile compounds, which is detected in some unifloral honey [29-32]. It was previously found in Taraxacum officinale honey in quite significant amounts (up to $20 \%$ in headspace) [29], in Satsuma Mandarin [32] and in thyme honey [30] for which it was proposed as a chemical marker if combined with other compounds. Benzyl nitrile also was reported in high amount in one analyzed Ivy honey sample from Corsica [16].

Myrtenal belongs to the class of terpenes found in a low number of honey examples. So far, it was detected (at a<smiles>O=c1cc[nH]c2ccccc12</smiles>

b<smiles>N#CCc1ccccc1</smiles>

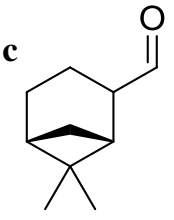

Fig. 2 Structure of compounds which could be treated as a biomarkers for Ivy honey a $4(1 H)$-quinolinone, b phenylacetonitrile, c myrtenal

significant level) only in Polish Salix spp. honey [33] and in lower amounts in manuka, clover and pohutukawa honey [34]. Structures of mentioned potential markers for $H$. helix honey are presented on Fig. 2.

Extracts obtained by USE and SPE extraction were also subject to the HPTLC analysis. As it was described previously, the obtained bands on HPTLC plates create unique patterns. Figure $3 a, b$ represents such fingerprint patterns for Ivy honeys obtained by both methods. As we observed in our unpublished research, honey of different botanical origins create their own unique fingerprint. For comparison, data for phacelia (Phacelia tanacetifolia Benth) honey (pollen analysis: $85 \%$ of phacelia pollen with $15 \%$ of other one) are presented in Fig. 3c. It seems that the most important characteristic of $H$. helix honey, after derivatization, is the presence of bands at $R_{\mathrm{f}}=0.30$ of a deep brown color and $R_{\mathrm{f}}=0.39$ of an intense blue color (seen only under irradiation at $254 \mathrm{~nm}$ ). Before derivatization, the most diagnostic part is the presence of bands at $R_{\mathrm{f}}=0.35$ and $R_{\mathrm{f}}=0.50$, which also gave strong signals in the profile generated based on the HPTLC image (Fig. 3b). The characteristic bands with their color description for the samples after derivatization are collected in Table 3. Moreover, it is noticeable that in extracts obtained by the USE method, more bands between values of $0.5-1.0$ are observed than in the SPE extracts. 

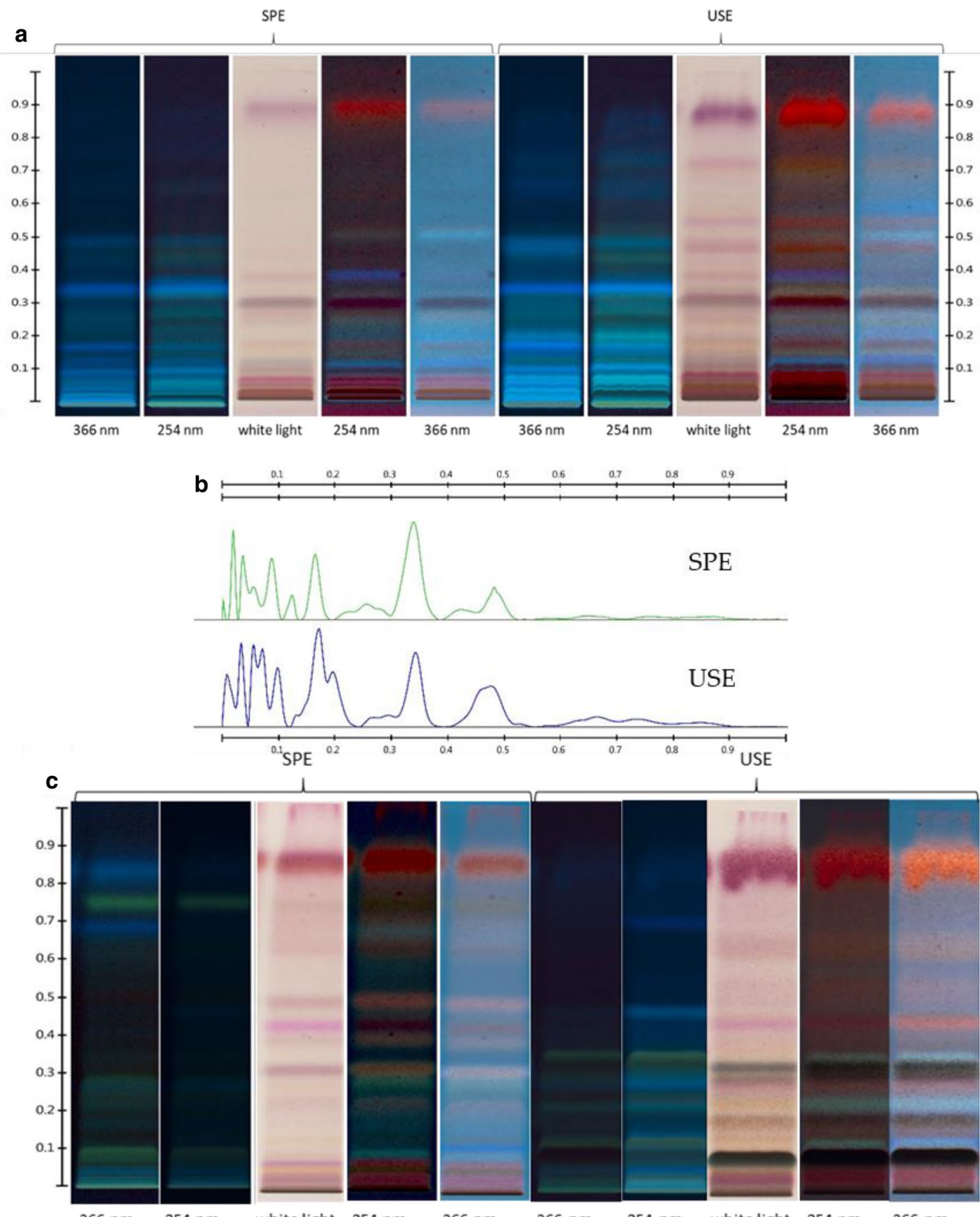

$366 \mathrm{~nm} \quad 254 \mathrm{~nm}$

white light

$366 \mathrm{~nm}$

$366 \mathrm{~nm}$

$254 \mathrm{~nm}$

white light

$254 \mathrm{~nm}$

$366 \mathrm{~nm}$

Fig. 3 a Exemplary HPTLC chromatograms represented unique fingerprint of Ivy honey after USE and SPE, b exemplary profile of Ivy honey generated based on the chromatogram picture obtained before

\section{Conclusions}

Hedera helix (Irish ivy) honey is a very rare brand on the market and is offered nearly exclusively in Ireland as a prized therapeutic food. In this paper, the volatile components of derivatization under at $366 \mathrm{~nm}$, $\mathbf{c}$ exemplary HPTLC chromatograms represented unique fingerprint of phacelia honey after USE and SPE

this honey were analyzed for the first time. Various methods for the isolation of these volatiles were used to comprehensively characterize the chemical fingerprint of this honey. The most representative profile of the chemicals was obtained by HS-SPME analysis when using two different 
Table 3 Characteristic $R_{\mathrm{f}}$ values in HPTLC analysis of $H$. helix honey

\begin{tabular}{|c|c|c|c|c|c|c|c|c|c|c|c|}
\hline \multicolumn{6}{|l|}{ SPE } & \multicolumn{6}{|l|}{ USE } \\
\hline \multicolumn{2}{|c|}{$366 \mathrm{~nm}$} & \multicolumn{2}{|c|}{$254 \mathrm{~nm}$} & \multicolumn{2}{|c|}{ White light } & \multicolumn{2}{|c|}{$366 \mathrm{~nm}$} & \multicolumn{2}{|c|}{$254 \mathrm{~nm}$} & \multicolumn{2}{|c|}{ White light } \\
\hline$R_{\mathrm{f}}$ & Color & $R_{\mathrm{f}}$ & Color & $R_{\mathrm{f}}$ & Color & $R_{\mathrm{f}}$ & Color & $R_{\mathrm{f}}$ & Color & $R_{\mathrm{f}}$ & Color \\
\hline 0.49 & Light blue & 0.39 & Blue & 0.30 & Deep brown & 0.49 & Light blue & 0.58 & Weak orange & 0.58 & Violet \\
\hline 0.30 & Deep brown & 0.30 & Deep brown & 0.16 & Orange & 0.31 & deep brown & 0.49 & Deep orange & 0.49 & Violet \\
\hline 0.18 & Light brown & 0.18 & Deep orange & 0.12 & Green & 0.28 & light orange & 0.39 & Blue & 0.31 & Deep brown \\
\hline \multirow[t]{3}{*}{0.12} & Blue & 0.12 & Blue & 0.07 & Deep pink & 0.18 & light brown & 0.31 & Deep brown & & \\
\hline & & & & & & 0.12 & blue & 0.18 & Deep orange & & \\
\hline & & & & & & & & 0.10 & Blue & & \\
\hline
\end{tabular}

USE ultrasound solvent extraction, $S P E$ solid-phase extraction, $R_{f}$ values are average from three plates for each extract, $S D$ standard deviation was less than 0.02 for each band

types of fibers. On the other hand, the identification of $4(1 H)$-quinolinone was possible thanks to USE and SPE. A comparison of the obtained results showed that only a few compounds were identified in all extracts, which once more documented that the use of only one extraction method is not enough for creating a detailed chemical fingerprint of certain honey samples and the presence of several compounds rather than a specific one is characteristic of its botanical identification. Thus, $4(1 H)$-quinolinone, myrtenal and phenylacetonitrile were proposed as chemical markers of Irish honey. Moreover, the obtained results confirmed that the usage of HPTLC method is a precise approach for honey differentiation both as a single method and as a complementary method for GC-MS analysis. This is because the bands obtained on the HPTLC plate create a unique pattern, which enables simple visual authentication of honey. This visual identification could be automatized since it is reminiscent of a simple bar code system.

Acknowledgements This research was supported by National Science Centre, Poland Project 2014/2015/15/B/NZ9/02182.

\section{Compliance with ethical standards}

Conflict of interest All authors declare that they have no conflict of interest.

Compliance with ethics requirements This article does not contain any studies with human or animal subjects.

Open Access This article is distributed under the terms of the Creative Commons Attribution 4.0 International License (http://creativeco mmons.org/licenses/by/4.0/), which permits unrestricted use, distribution, and reproduction in any medium, provided you give appropriate credit to the original author(s) and the source, provide a link to the Creative Commons license, and indicate if changes were made.

\section{References}

1. Cuevas-Glory LF, Pino JA, Santiago LS, Sauri-Duch E (2007) A review of volatile analytical methods for determining the botanical origin of honey. Food Chem 103:1032-1043

2. Manyi-Loh CE, Ndip RN, Clarke AM (2011) Volatile compounds in honey: a review on their involvement in aroma botanical origin determination and potential biomedical activities. Int J Mol Sci 12(12):9514-9532

3. Jerković I, Tuberso CIG, Gugić M, Bubalo D (2010) Composition of Sulla (Hedysarum coronarium L.) honey solvent extractives determined by GC/MS: norisoprenoids and other volatile organic compounds. Molecules 15:6375-6385

4. Puscas A, Hosu A, Cimpoiu C (2013) Application of a newly developed and validated high-performance thin-layer chromatographic method to control honey adulteration. J Chromatogr A 1272:132-135

5. Kaskoniene V, Venskutonis PR (2010) Floral markers in honey of various botanical and geographic origins: a review. Compr Rev Food Sci Food Saf 9:620-634

6. Zhu X, Li S, Shan Y, Zhang Z, Li G, Su D, Liu F (2010) Detection of adulterants such as sweeteners materials in honey using near-infrared spectroscopy and chemometrics. J Food Eng 101:92-97

7. Moore JC, Spink J, Lipp M (2012) Development and application of a database of food ingredient fraud and economically motivated adulteration from 1980 to 2010. J Food Sci 77:118-126

8. Gheldof N, Wang XH, Engeseth NJ (2003) Buckwheat honey increases serum antioxidant capacity in humans. J Agric Food Chem 51:1500-1505

9. Schramm DD, Karim M, Schrader HR, Holt RR, Cardetti M, Keen CL (2003) Honey with high levels of antioxidants can provide protection to healthy human subjects. J Agric Food Chem 51:1732-1735

10. Oelschlaegel S, Pieper L, Staufenbiel R, Gruner M, Zeippert L, Pieper B, Koelling-Speer I, Speer K (2012) Floral markers of cornflower (Centaurea cyanus) honey and its peroxide antibacterial activity for an alternative treatment of digital dermatitis. J Agric Food Chem 60:11811-11820

11. Wegiera M, Smolarz HD, Jedruch M, Korczak M, Koproń K (2012) Cytotoxic effect of some medicinal plants from Asteraceae family on J-45.01 leukemic cell line-pilot study. Acta Pol Pharm 69:263-268

12. Garbacki N, Gloaguen V, Damas J, Bodart P, Tits M, Angenot L (1999) Anti-inflammatory and immunological effects of Centaurea cyanus flower-heads. J Ethnopharmacol 68:235-241 
13. Chodera A, Dąbrowska K, Sloderbach A, Skrzypczak L, Budzianowski J (1991) The effect of flavonoids fraction of Solidago species on diuretic and electrolytes concentration. Acta Pol Pharm 48:35-37

14. Bianchi F, Careri M, Musci M (2005) Volatile norisoprenoids as markers of botanical origin of Sardinian strawberry-tree (Arbutus unedo L.) honey: characterisation of aroma compounds by dynamic headspace extraction and gas chromatography-mass spectrometry. Food Chem 89:527-532

15. Lixandru M (2017) Properties and benefits of ivy honey. https:// www.natureword.com/properties-and-benefits-of-ivy-honey/. Accessed 7 Jan 2018

16. Yang Y, Battesi MJ, Costa J, Paolini J (2014) Melissopalynological and volatile analysis of honeys from Corsican Arbutus unedo habitat. Nat Prod Commun 9:1523-1526

17. Louveaux J, Maurizio A, Vorwohl G (1978) Methods of melissopalinology. Bee World 59:139-157

18. Jasicka-Misiak I, Makowicz E, Stanek N (2017) Polish yellow sweet clover (Melilotus officinalis L.) honey chromatographic fingerprints and chemical markers. Molecules 22:138

19. Jasicka-Misiak I, Makowicz E, Stanek N (2018) Chromatographic fingerprint antioxidant activity and colour characteristic of polish goldenrod (Solidago virgaurea L.) honey and flower. Eur Food Res Technol. https://doi.org/10.1007/s00217-018-3034-3

20. Jerković I (2013) Volatile benezene derivatives as honey biomarkers. Synllet 24:2331-2334

21. Jerkovic I, Kuś PM (2014) Terpenes in honey: occurrence origin and their role as 340 chemical biomarkers. RSC Adv 4:31710-31728

22. Viuda-Martos M, Ruiz-Navajas Y, Zaldivar-Cruz JM, Kuri V, Fernández-López J, Carbonell-Barrachina ÁA, Pérez-Álvarez J (2010) Aroma profile and physic-chemical properties of artisanal honeys form Tabasco Mexico. Int J Food Sci Technol 45:1111-1118

23. Michael JP (2008) Quinoline quinazoline and acridone alkaloids. Nat Prod Rep 25:166-187

24. Marella A, Tanwar OP, Saha R, Ali M, Srivastava R, Akhter S, Shaquiquzzaman M, Alam M MM (2013) Quinoline: a versatile heterocyclic. Saudi Pharm J 21:1-12
25. Souto AL, Tavares JF, da Silva MS, Diniz MFFM, Athayde-Filho PF, Filho JMB (2011) Anti-inflammatory activity of alkaloids: an update from 2000 to 2010. Molecules 16:8515-8534

26. Cho JY, Bae SH, Kim HK, Lee ML, Choi YS, Jin BR, Lee HJ, Jeong HY, Lee YG, Moon JH (2015) New quinolinone alkaloids from chestnut (Castanea crenata Sieb) honey. J Agric Food Chem 63:3587-3592

27. Schievano E, Morelato E, Facchin C, Mammi S (2013) Characterization of markers of botanical origin and other compounds extracted from unifloral honeys. J Agric Food Chem 61:1747-1755

28. Beretta G, Artali R, Caneva E, Orlandini S, Centini M, Facino RM (2009) Quinoline alkaloids in honey: further analytical (HPLCDAD-ESI-MS multidimensional diffusion-ordered NMR spectroscopy) theoretical and chemometric studies. J Pharm Biomed Anal 50:432-439

29. Jerković I, Marijanović Z, Kranjac M, Radonić A (2015) Comparison of different methodologies for detailed screening of Taraxacum officinale honey volatiles. Nat Prod Commun 10(2):357-360

30. Alissandrakis E, Tarantilis PA, Harizanis PC, Polissiou M (2007) Comparison of the volatile composition in thyme honeys from several origins in Greece. J Agric Food Chem 55:8152-8157

31. Jerković I, Marijanović Z, Kezić J, Gugić M (2009) Headspace volatile and semi-volatile organic compounds diversity and radical scavenging activity of ultrasonic solvent extracts from Amorpha fruticosa honey samples. Molecules 14:2717-2728

32. Jerković I, Prdun S, Marijanović Z, Zekić M, Bubalo D, Svecnjak L, Tuberoso CIG (2016) Traceability of Satsuma mandarin (Citrus unshiu Marc.) honey through nectar/honey-sac/honey pathways of the headspace volatiles and semi-volatiles: chemical markers. Molecules 21:1302

33. Jerković I, Kuś PM, Tuberoso CI, Šarolić M (2014) Phytochemical and physical-chemical analysis of Polish willow (Salix spp.) honey: identification of the marker compounds. Food Chem 145:8-14

34. Revell LE, Morris B, Manley-Harris M (2014) Analysis of volatile compounds in New Zealand unifloral honeys by SPME-GC-MS and chemometric-based classification of floral source. Food Meas 8:81-91 